\title{
Statistical Modelling of Ultrasonic-Aided Extraction of Elaeis guineensis Leaves for Better-Quality Yield and Total Phenolic Content
}

\author{
Nissha Bharrathi Romes ${ }^{1,2}$, Mariani Abdul Hamid ${ }^{3}$, Siti Ernieyanti Hashim ${ }^{1}$, and Roswanira Abdul \\ Wahab $^{1,2, *}$ \\ ${ }^{1}$ Department of Chemistry, Faculty of Science, Universiti Teknologi Malaysia, 81310 UTM Skudai, Johor, Malaysia \\ ${ }^{2}$ Enzyme Technology and Green Synthesis Group, Faculty of Science, Universiti Teknologi Malaysia, \\ 81310 UTM Skudai, Johor, Malaysia
}

${ }^{3}$ Institute of Bioproduct Development, Universiti Teknologi Malaysia, 81310 UTM Johor Bahru, Malaysia

\author{
* Corresponding author: \\ email: roswanira@kimia.fs.utm.my
}

Received: December 5, 2018

Accepted: January 11, 2019

DOI: $10.22146 /$ ijc. 41603

\begin{abstract}
The present study highlighted the statistical modelling of an ultrasonic-aided extraction (UAE) of Elaeis guineensis leaves extract for maximal extraction yield (EY) and total phenolic content (TPC). A Box-Behnken design investigated the effects of ethanol concentration $\left(X_{1}: 0-100 \%\right)$, extraction time $\left(X_{2}: 5-55 \mathrm{~min}\right)$, the solvent-to-solid ratio $\left(X_{3}: 15: 1-35: 1 \mathrm{~mL} / \mathrm{g}\right)$ and sonification amplitude $\left(X_{4}: 20-100 \%\right)$. Under optimized conditions, the highest EY of $14.38 \%$ was attained using $50 \%(v / v)$ ethanol:water ratio, $55 \mathrm{~min}, 35 \mathrm{~mL} / \mathrm{g}$ solvent-to-solid ratio, 60\% sonication amplitude, whereas maximum TPC was $209.70 \mathrm{mg}$ gallic acid equivalent $(G A E) / g$ [50\% (v/v) ethanol:water ratio, $30 \mathrm{~min}$, $25 \mathrm{~mL} / \mathrm{g}$ solvent-to-solid ratio, 60\% sonication amplitude]. Second-order polynomial models of EY and TPC showed the $R^{2}$ value corresponding to 0.9303 and 0.9500 , respectively, indicating their significance $(p<0.05)$ to predict the responses. HPLC chromatograms revealed gallic acid and catechin were present in the UAE extracts. UAE technique afforded better EY (14.38\%) and TPC (209.70 $\mathrm{mg}$ GAE/g) than maceration (3.73\%, 85.23 $\mathrm{mg} \mathrm{GAE/g}$ ) and Soxhlet (6.86\%, $102.13 \mathrm{mg} \mathrm{GAE} / \mathrm{g})$ extractions, as based on scanning electron micrographs of untreated, UAE, macerated and Soxhlet treated samples. Cell walls of ultrasonic-treated E. guineensis leaves were visibly disrupted to facilitate the higher release of bioactive plant materials, thus justifying the higher EY and TPC. The application of ultrasound appeared to remarkably increase the extraction efficiency of E. guineensis leaves to extract as compared to the conventional methods.
\end{abstract}

Keywords: ultrasonic-aided extraction; Elaeis guineensis; extraction yield; total phenolic content; response surface methodology

\section{- INTRODUCTION}

Elaeis guineensis Jacq. or commonly known as palm oil tree belonging to the family Arecaceae is an oilproducing crop that grows perennially in a tropical climate [1-2]. The carotenoid-rich orange-red colored oil is obtained from the thinly-skinned fleshy fruits, as well from the mesocarp and kernels [3]. Being the most important agricultural crop in Malaysia, palm oil is the fourth largest contributor to the nation's economy [4]. Nonetheless, biomass from oil palm industries generated from pruning, replanting and milling activities are currently underutilized, as apparent from the insignificant conversions of oil palm biomass into valueadded products [5]. The biomass of the oil palm constitutes oil palm fronds, oil palm trunk, empty fruit bunches, palm kernel shells, mesocarp fibers and palm oil mill effluent [6]. In fact, oil palm leaves (OPL) make up the largest portion amounting to 53\% dry weight of the total biomass [7]. As far as applicability of OPL is concerned, it is limited as ruminant feed and food flavoring agents [8]. Therefore, utilizing the cellulosic 
materials in OPL can improve agriculture sustainability while reducing the quantity of this biomass [9].

Studies have shown that OPL extracts (OPLE) contain a myriad of beneficial water-soluble flavonoids and phenolic acids, as well as oil-soluble vitamin E, $\alpha$ - and $\beta$-tocopherols [10]. These compounds are recognized for their potency as antioxidants, anti-mutagenic, antiinflammatory and anti-cancer agents, as well as several other nutritional and health benefits [11-12]. Other bioactive ingredients exhibiting anti-tyrosinase and antimicrobial activities are also present in the OPLE, whereas certain compounds can protect the human skin against ultraviolet (UV) radiation, implying their usability for topical application [13]. Specifically, catechins viz. epigallocatechin $(0.08 \%)$, catechin $(0.30 \%)$, epicatechin $(0.01 \%)$, epigallocatechin gallate $(0.28 \%)$ and epicatechin gallate $(0.05 \%)$ are among the reported phenolic compounds existing in OPLE [14]. There are claims of glycosylated flavonoids, ferulic acid, gallic acid, protocatechuic acid and carotenoids being present, too [15].

Considering the high presence of beneficial phytochemicals in the OPLE, the study, therefore, emphasizes that they may be valuable as active ingredients in topical creams. This is in light of the alarmingly widespread use of synthetically produced anti-oxidants, for instance, butylated hydroxyanisole, butylated hydroxytoluene, tertiary butyl hydroquinone and propyl gallate as active ingredients in such creams. It is somewhat worrying as these substances are thought to be among the causal agents of skin cancer [16-17]. In this perspective, their replacement with natural plant-based antioxidants such as phytopolyphenols, flavonoids, vitamin $\mathrm{C}$ and carotenoids as active ingredients in creams, may offer a safer alternative. Moreover, these plant-based compounds are known as good scavengers of hazardous free-radicals [18].

To promote the use of plant bioactive compounds in cosmeceutical topical creams, their process recovery must be judiciously carried out to ensure retention of their bioactivity. This is because conventional extraction methods that rely on physical treatments, for example, heating, refluxing, boiling and Soxhlet extraction tend to result in major losses of bioactivity due to oxidation, ionization and hydrolysis of plant compounds during prolonged extraction time, alongside the undesirable employment of high quantities of solvents [19]. These issues may be circumvented using modern techniques, for instance, supercritical fluid extraction, subcritical water, and accelerated solvent extraction, high hydrostatic pressure processing, microwave-assisted and Ultrasonic-Aided Extraction (UAE) to extract plant materials [20-22]. Herein, the work reported here was focused on the use of UAE to extract valuable plant phytochemicals. In conjunction with being cheap and simple to operate, UAE is highly efficient and leads to good extraction efficiency [23]. Unlike the aforementioned simple physical treatments, UAE acoustically induced cavitation rigorously rupture plant cell walls and synergistically improve solvent penetrability into the plant matrix while reducing particles size. A higher surface of contact between trapped bioactive compounds and the solvent medium is achieved afterwards, facilitating better extraction [24-25].

In this study, the UAE based on the Box-Behnken Design (BBD) was optimized for parameters solvent concentration, extraction time, solvent-to-solid ratio and sonication amplitude to account for the highest yield and total phenolic content in the OPLE. Suitability of this mathematical and statistical tool has been established in a myriad of experimental trials for different processes. In fact, the BBD has been proven excellent for evaluating and observing influences, as well as interactions of multiple factors in any given process; benefits that are unseen in the one-variable-at-a-time technique [26-27]. Thus, the objective of this study was to seek the best aforementioned UAE conditions for maximizing the extraction yield and total phenolic content of E. guineensis leaves extract. For better comprehension of the UAE extraction efficacy, conventional extraction methods using Soxhlet extraction and maceration on E. guineensis leaves were also performed and the results were compared to that of UAE. Scanning electron micrographs were used to observe and accentuate the morphological differences between the untreated, ultrasonically treated and $E$. guineensis leave samples subjected to maceration and 
Soxhlet extraction. It is hypothesized the efficient extraction of phytochemicals trapped in OPL by the UAE is due to the available higher contact area that stems from the acoustically ruptured plant cell walls. To the best of our knowledge, this is the first study detailing the use of a UAE of oil palm leaves for optimizing the extraction yield and total phenolic content.

\section{- EXPERIMENTAL SECTION}

\section{Materials}

\section{Plant materials}

Fresh Oil Palm Leaves (OPL) were collected from a plantation on the grounds of Universiti Teknologi Malaysia, Johor in October 2017. The OPL was left to airdry for a week before undergoing cutting and grinding into a powder. The powdered samples were kept in ziplocked plastic bags and stored at room temperature until further use.

\section{Chemicals and reagents}

Folin-Ciocalteu's phenol reagent, (+)-catechin hydrate, and sodium carbonate were purchased from Sigma-Aldrich (St. Louis, USA). Gallic acid, sodium nitrite, and aluminum chloride hexahydrate were purchased from Merck (Darmstadt, Germany). Analytical grade ethanol (99.86\% mass fraction purity) used for the extraction was procured from Haymankimia (Essex, England), while HPLC grade ethanol was from Sigma-Aldrich (St. Louis, MO, USA). All other chemicals used in this study were of analytical grade. Millipore Milli-Q water purification system was used to produce 18 $\mathrm{m} \Omega$ deionized water that was used in all analyses.

\section{Procedure}

\section{Ultrasonic-aided extraction of OPL}

Ultrasonic-Aided Extraction (UAE) of the OPL was performed using an ultrasonic probe Sonics Vibra Cell (America) equipped with a digital control system that controls sonication time and amplitude. In all experiments, ultrasonication on OPL was performed at $20 \mathrm{kHz}$ frequency and constant power of $130 \mathrm{~W}$ under a constant temperature of $25{ }^{\circ} \mathrm{C}$. This was to avoid structural alteration and thermal degradation of the biologically active compounds [28]. Dry OPL ( $1 \mathrm{~g})$ was weighed and transferred each into centrifuge tubes $(50 \mathrm{~mL})$ containing designated volumes of ethanol (15, 25 and $35 \mathrm{~mL})$ at varying concentrations $(0,50,100 \%$ $\mathrm{v} / \mathrm{v})$. The suspensions were homogenized using a homogenizer IKA T18 Digital Ultra Turrax (Germany) at $10,000 \mathrm{rpm}$ for $40 \mathrm{~s}$ prior to UAE. The samples were then sonicated and assessed for the effects of solvent concentration (0-100\%), solvent-to-solid ratio (15:1, $25: 1$ and $35: 1 \mathrm{~mL} / \mathrm{g})$, extraction time $(5,30,55 \mathrm{~min})$ and sonication amplitude $(20,60,100 \%)$ for the responses, Extraction Yield (EY) and Total Phenolic Content (TPC). Sample collection was done by centrifuging each sample mixture for $15 \mathrm{~min}$ at $4,000 \mathrm{rpm}$, the supernatants were collected and filtered through a Whatman No. 1 filter paper. The solvent was removed using a rotary evaporator under reduced pressure at 40 ${ }^{\circ} \mathrm{C}$ to obtain the crude extract, and then lyophilized for $48 \mathrm{~h}$. Each crude sample was accurately weighed using an analytical balance with a sensitivity of $0.1 \mathrm{mg}$ by Shimadzu Philippines Manufacturing Inc. (Philippines) until a constant weight was attained. Samples were then stored at $4{ }^{\circ} \mathrm{C}$ until further analysis. Percentage of extraction yield (\%) was determined using Eq. (1).

Yield $(\%)=\frac{\text { Weight of sample after freeze drying }(\mathrm{g})}{\text { Weight of dried sample }(\mathrm{g})} \times 100 \%$

\section{Determination of total phenolic content (TPC)}

Folin-Ciocalteu (FC) phenol method with slight modifications was used to estimate the TPC of the OPLE. The readings were colorimetrically determined by a UV-Visible spectrophotometer (UV-1601PC, Shimadzu), based on an oxidation/reduction reaction [29]. OPLE $(0.2 \mathrm{~mL})$ was mixed with FC reagent $(0.2 \mathrm{~mL})$ and deionized water $(1.8 \mathrm{~mL})$, followed by further additions of $7 \%(\mathrm{w} / \mathrm{v}) \mathrm{Na}_{2} \mathrm{CO}_{3}(2 \mathrm{~mL})$ and deionized water $(0.8 \mathrm{~mL})$ after $5 \mathrm{~min}$. The extracts were homogenized and left to stand for $30 \mathrm{~min}$ before the absorbance was read at $765 \mathrm{~nm}$. Absolute ethanol, pure water and a mixture of ethanol and water were used as blanks for the different OPL samples extracted using absolute ethanol, pure water and a mixture of ethanol, respectively. Three different calibration curves for extracts of absolute ethanol, pure water and a mixture of ethanol and water (concentrations varying from 
$0-100 \mu \mathrm{g} \mathrm{mL}^{-1}$ ) were prepared using gallic acid as the standard (Fig. 1(a-c)) and each analysis was triplicated. The results were expressed in $\mathrm{mg}$ gallic acid equivalent (GAE) per gram of extract (mg GAE/g extract) as shown in Eq. (2).

$\mathrm{T}=\mathrm{C} \times \frac{\mathrm{V}}{\mathrm{M}}$

where $\mathrm{T}$ is the total phenolic content in $\mathrm{mg} \mathrm{g}^{-1}$ of the extract expressed as GAE; $\mathrm{C}$ is the concentration of gallic acid established from the calibration curve in $\mathrm{mg} \mathrm{mL}^{-1} ; \mathrm{V}$ is the volume of the extract solution in $\mathrm{mL}$, and $\mathrm{M}$ is the weight of the extracts in $\mathrm{g}$.

\section{Determination of total flavonoids content (TFC) of the highest TPC crude}

TFC was determined spectrophotometrically using a colorimetric method based on aluminum chloride $\left(\mathrm{AlCl}_{3}\right)$ with minor modifications [29-31]. A sample $(2 \mathrm{~mL})$ was mixed with $\mathrm{NaNO}_{2}$ solution $(0.6 \mathrm{~mL}, 5 \%$, w/v),
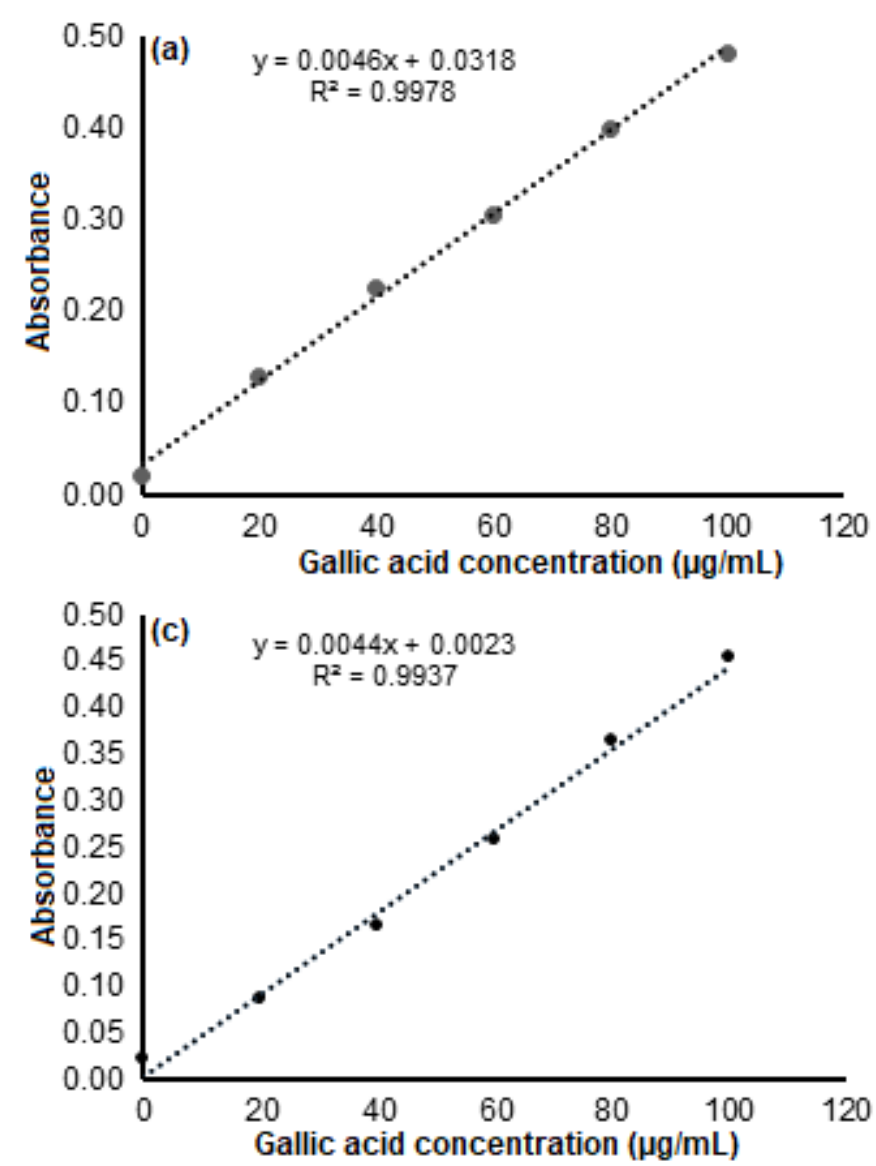

followed by the addition of $\mathrm{AlCl}_{3}(1 \mathrm{~mL}, 2 \%$, w/v) after 5 $\mathrm{min}$. The mixture was mixed thoroughly and incubated for $5 \mathrm{~min}$. The mixture was then neutralized with $\mathrm{NaOH}$ solution $(0.5 \mathrm{~mL}, 1 \mathrm{~mol} / \mathrm{L})$, left to stand for $10 \mathrm{~min}$ at room temperature and the absorbance read at $510 \mathrm{~nm}$. The linearity range of the prepared calibration curve (Fig. 1(d)) was between $0.00-0.10 \mathrm{mg} / \mathrm{mL}$ and the TFC was estimated using a catechin hydrate standard curve, reported as $\mathrm{mg}$ catechin hydrate equivalents (CAE)/g of dried weight (DW) (Eq. 3). All absorbances were measured in triplicate;

$\mathrm{C}=\frac{\mathrm{CV}}{\mathrm{m}}$

where $\mathrm{C}$ is the total content of flavonoid compounds in $\mathrm{mg} / \mathrm{g}$ of plant extract as CAE; $\mathrm{C}$ is the concentration of catechin hydrate established from the calibration curve in $\mathrm{mg}^{-1} \mathrm{~mL} ; \mathrm{V}$ is the volume of the extract in $\mathrm{mL} ; \mathrm{m}$ is the weight of the crude plant extracts in $g$.
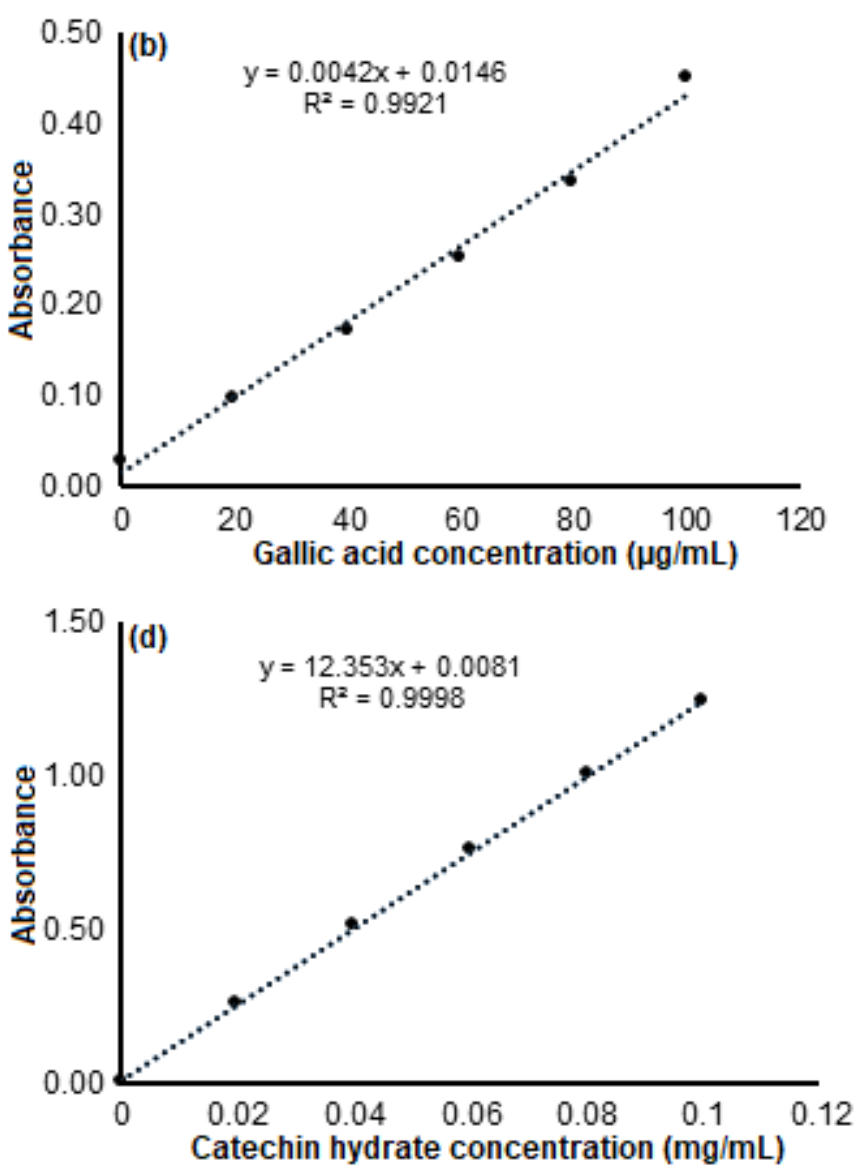

Fig 1. Calibration curve of (a) gallic acid in $100 \%$ water, (b) gallic acid in $100 \%$ ethanol, (c) gallic acid in $50 \%$ ethanol for determination of TPC, and (d) catechin hydrate in $50 \%$ ethanol for determination of TFC value in OPLE 


\section{Maceration extraction (ME) and soxhlet extraction (SE)}

Ground dried OPL ( $1 \mathrm{~g}$ ) was mixed with an ethanol solution $(200 \mathrm{~mL}, 50 \%)$ and shaken on an orbital shaker (12 VDC 1.5 Amps 18 Watts, Seastar, China) at room temperature for $24 \mathrm{~h}$. The extractant was collected, dried as specified in Section 2.3 and stored at $4{ }^{\circ} \mathrm{C}$ until further analysis. For the Soxhlet extraction, ground OPL ( $1 \mathrm{~g})$ was placed over a Whatman filter paper and refluxed in ethanol $(200 \mathrm{~mL}, 50 \%, \mathrm{v} / \mathrm{v})$ at $95{ }^{\circ} \mathrm{C}$ for $24 \mathrm{~h}$. The extractant was collected, dried (Section 2.3) and stored at $4{ }^{\circ} \mathrm{C}$. Extraction yields and TPCs for both methods were calculated as per Eq. (1) and (2) [32].

\section{Scanning electron microscopy (SEM)}

Ground OPL samples either untreated or ultrasound-treated, as well as those obtained from the Soxhlet and maceration extraction samples, were subjected to SEM to observe changes in morphology of the plant materials, as the result from the above experiments. A SEM (JEOL JEM-6700F) operated at 5kV was used in the analyses, where the four differently treated dried samples of OPL were deposited on silicon wafers and were sputter-coated with a thin layer of gold to avoid charging under the electron beam [9].

\section{HPLC analysis for gallic acid and catechin}

HPLC analysis was carried out according to the manufacturer's protocol for the instrument Agilent Technologies Model 1123 equipped with a diode-array detector, Agilent Software and a C18 column $(5.0 \mu \mathrm{m}$, $250 \mathrm{~mm} \times 4.6 \mathrm{~mm}$; Agilent). The mobile phase consisted of ethanol:water:orthophosphoric acid in the ratio of 20:79.9:0.1, respectively, moving isocratically at a rate of $1.0 \mathrm{~mL} / \mathrm{min}$. The injected volume was $5 \mu \mathrm{L}$ and the detection wavelength of the UV detector was $270 \mathrm{~nm}$. For detection of catechin, HPLC analysis on the extract was carried out using Waters 2695 series HPLC equipped with an autosampler, PDA detector, Empower Software and a C18 column $(5.0 \mu \mathrm{m}, 150 \mathrm{~mm} \times 4.6 \mathrm{~mm}$; Waters), operated at $30{ }^{\circ} \mathrm{C}$. The mobile phase was comprised of solvent A ( $0.1 \%$ acetic acid) and solvent B (acetonitrile), and flowed under an isocratic program (95\% A: $5 \%$ B) at $0.8 \mathrm{~mL} / \mathrm{min}$, whereas the injected volume and detection wavelength was $20 \mu \mathrm{L}$ and $280 \mathrm{~nm}$, respectively.

\section{Box-Behnken experimental design}

Prior to optimization, a screening study was performed to estimate the logic range of optimization experiments, as well as to determine factors that were relevant in affecting the two responses in the study. A four-factor-three-level Box-Behnken design (BBD) was used in the optimization experiment, in which only relevant factors that influence the efficiency of EY and TPC were assessed. The BBD experiment was carried out in random order and comprised of 29 combinations which include five replicates for the central points. Factors of ethanol concentration $\left(\%, \mathrm{X}_{1}\right)$, extraction time $\left(\mathrm{min}, \mathrm{X}_{2}\right)$, the solvent-to-solid ratio $\left(\mathrm{mL} / \mathrm{g}, \mathrm{X}_{3}\right)$ and sonification amplitude $\left(\%, \mathrm{X}_{4}\right)$ were examined and their ranges were tabulated in Table 1 . The temperature of the UAE was kept at room temperature to avoid degradation of temperature-sensitive compounds. The second-order (quadratic) polynomial response surface model which delineates the relationship between the experimental results is as follows (Eq. 4):

$\mathrm{Y}=\mathrm{b}_{0}+\sum_{\mathrm{i}=1}^{\mathrm{n}}\left(\mathrm{bixi}_{\mathrm{i}}\right)+\sum_{\mathrm{i}=1}^{\mathrm{n}}\left(\mathrm{biix}^{2}{ }_{\mathrm{ii}}\right)+\sum_{\mathrm{ij}=1}^{\mathrm{n}}\left(\mathrm{b}_{\mathrm{j} j \mathrm{jxx}}\right)$

where $\mathrm{Y}$ is the predicted variable (EY or TPC), $\mathrm{b}_{0}$ is the constant; $x_{i}$ stands for the coded levels of the design variable (solvent concentration, extraction time, solvent-to-solid ratio, energy of sonification amplitude and $\mathrm{n}$ is the number of tested variables $(\mathrm{n}=4), \mathrm{b}_{\mathrm{i}}=$ linear effects, $b_{i i}=$ quadratic effects and $b_{i j}=$ interaction effects.

Table 1. Three levels of the independent variables in the BBD of the UAE

\begin{tabular}{llcrrr}
\hline \multirow{2}{*}{ Independent Variables } & \multirow{2}{*}{ Units } & \multirow{2}{*}{ Symbols } & \multicolumn{3}{c}{ Coded Levels } \\
\cline { 4 - 6 } & & & -1 & 0 & +1 \\
\hline Ethanol concentration & $\% \mathrm{v} / \mathrm{v}$ & $\mathrm{X}_{1}$ & 0 & 50 & 100 \\
Extraction time & $\mathrm{min}$ & $\mathrm{X}_{2}$ & 5 & 30 & 55 \\
Solvent-to-solid ratio & $\mathrm{mL} / \mathrm{g}$ & $\mathrm{X}_{3}$ & 15 & 25 & 35 \\
Energy of sonification amplitude & $\%$ & $\mathrm{X}_{4}$ & 20 & 60 & 100 \\
\hline
\end{tabular}

Nissha Bharrathi Romes et al. 


\section{Statistical analysis}

The regression analysis and the optimization of RSM were analyzed by the Design-Expert 7.1.6 software. The analysis of variance (ANOVA) was carried out to check the statistical significance $(p<0.05)$ of the independent variables. The coefficient of determination $\left(\mathrm{R}^{2}\right)$, lack of fit, adequate precision which measures the signal to noise ratio, adjusted coefficient of determination $\left(\operatorname{adj} . \mathrm{R}^{2}\right)$, coefficient of variation (C.V), and Fischer's test value (F-value) were used to examine the adequacy of UAE models.

\section{- RESULTS AND DISCUSSION}

\section{Model Fitting and Process Optimization}

Response Surface Methodology (RSM) is an effective analytical tool to measure the interaction and correlation process variables and corresponding responses, along with the effects of optimized multiple variables on the responses [33-34]. The current study was conducted to seek the optimal conditions for maximizing extraction yield (EY) and total phenolic contents (TPC)
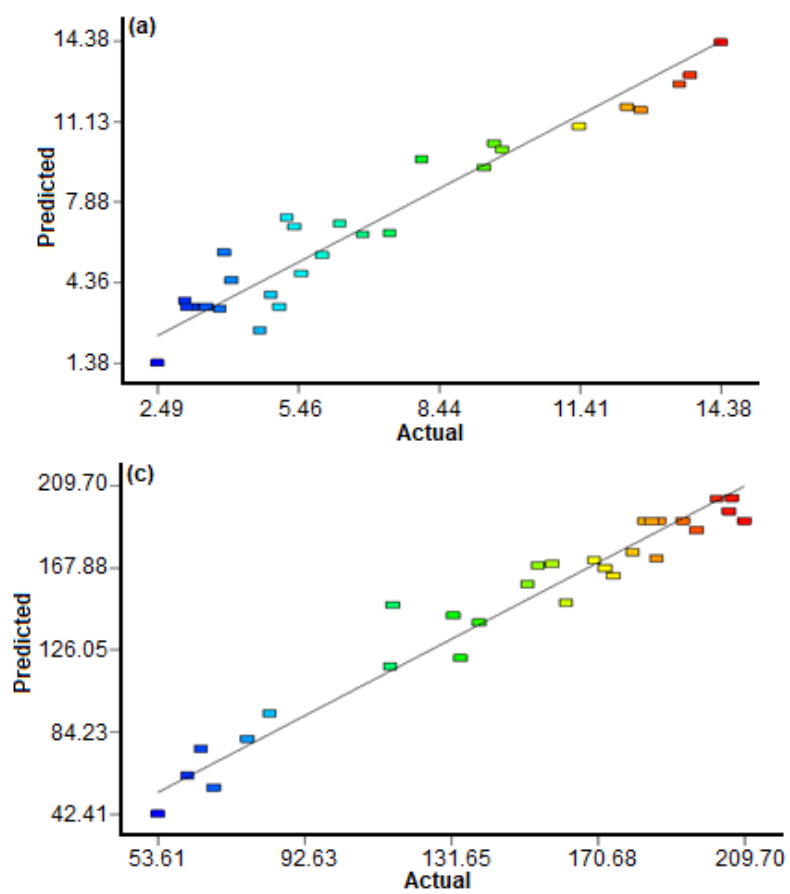

Fig 2. Comparison between the (a) predicted and actual values and (b) deviation of the reference point for EY, as well as (c) predicted and actual values and (d) deviation of the reference point for TPC, for the effect of $\left(\mathrm{X}_{1}\right)$ solvent concentration, $\left(\mathrm{X}_{2}\right)$ extraction time, $\left(\mathrm{X}_{3}\right)$ solvent-to-solid ratio and $\left(\mathrm{X}_{4}\right)$ sonication amplitude

Nissha Bharrathi Romes et al. from E. guineensis leaves. The BBD used in this study was fitted to second-order polynomial equations (linear, two-factorial, quadratic and cubic), in which a quadratic model was found to best describe the ultrasonic-aided extraction (UAE) of E. guineensis leaves (OPL). Two models generated by the study were tested for statistical significances and adequacies based on their $\mathrm{p}$ - and Fvalues, the coefficient of determinations $\left(\mathrm{R}^{2}\right)$ and adjusted determination of coefficients (adj. $R^{2}$ ) from analysis of variances (ANOVA). For brevity, a model with a p-value of less than 0.05 , indicates the model is significant and a p-value of below 0.0001 implies a highly significant model. along with the experimental and predicted responses for the EY and TPC are tabulated in Table 1, 2 and 4, respectively. The regressed experimental data corresponding to ANOVA (Table 3 and Table 5) exhibited that EY and TPC, respectively, were well delineated by a quadratic polynomial model and equations. The experimental results of EY (Fig. 2(a)) and TPC (Fig. 2(c)) agreed well with the predicted values, as
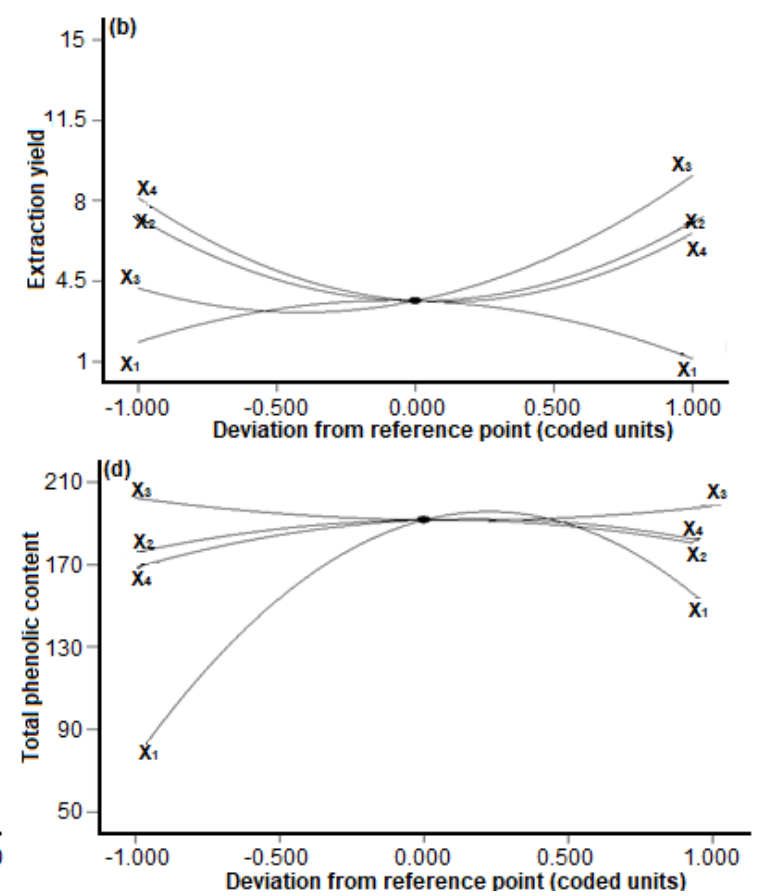

The range of the UAE processing variables, levels 
Table 2. BBD experimental design and results for EY

\begin{tabular}{|c|c|c|c|c|c|c|}
\hline Run & $X_{1}$ & $X_{2}$ & $X_{3}$ & $X_{4}$ & $\begin{array}{c}\text { Experimental Yield } \\
(\%)\end{array}$ & $\begin{array}{c}\text { Expected Yield } \\
(\%)\end{array}$ \\
\hline 1 & 50 & 5 & 15 & 60 & 8.07 & 9.60 \\
\hline 2 & 50 & 5 & 25 & 20 & 12.40 & 11.71 \\
\hline 3 & 50 & 30 & 35 & 20 & 13.73 & 12.99 \\
\hline 4 & 100 & 30 & 25 & 100 & 5.53 & 4.98 \\
\hline 5 & 50 & 30 & 25 & 60 & 5.07 & 3.64 \\
\hline 6 & 50 & 55 & 35 & 60 & 14.38 & 14.32 \\
\hline 7 & 0 & 30 & 25 & 20 & 5.22 & 7.23 \\
\hline 8 & 0 & 5 & 25 & 60 & 7.39 & 6.63 \\
\hline 9 & 50 & 30 & 25 & 60 & 3.27 & 3.64 \\
\hline 10 & 50 & 30 & 35 & 100 & 13.51 & 12.63 \\
\hline 11 & 0 & 55 & 25 & 60 & 4.88 & 4.11 \\
\hline 12 & 50 & 30 & 15 & 20 & 9.39 & 9.26 \\
\hline 13 & 50 & 5 & 35 & 60 & 11.39 & 10.92 \\
\hline 14 & 50 & 30 & 25 & 60 & 3.22 & 3.64 \\
\hline 15 & 100 & 5 & 25 & 60 & 3.81 & 3.57 \\
\hline 16 & 50 & 5 & 25 & 100 & 9.60 & 10.24 \\
\hline 17 & 50 & 55 & 25 & 20 & 12.69 & 11.59 \\
\hline 18 & 50 & 30 & 25 & 60 & 3.12 & 3.64 \\
\hline 19 & 0 & 30 & 35 & 60 & 6.34 & 7.00 \\
\hline 20 & 100 & 30 & 35 & 60 & 5.38 & 6.88 \\
\hline 21 & 100 & 30 & 15 & 60 & 2.49 & 1.38 \\
\hline 22 & 0 & 30 & 25 & 100 & 3.07 & 3.89 \\
\hline 23 & 100 & 30 & 25 & 20 & 4.06 & 4.70 \\
\hline 24 & 50 & 55 & 15 & 60 & 3.90 & 5.84 \\
\hline 25 & 0 & 30 & 15 & 60 & 4.65 & 2.70 \\
\hline 26 & 50 & 55 & 25 & 100 & 9.76 & 10.00 \\
\hline 27 & 100 & 55 & 25 & 60 & 5.97 & 5.73 \\
\hline 28 & 50 & 30 & 15 & 100 & 6.83 & 6.56 \\
\hline 29 & 50 & 30 & 25 & 60 & 3.53 & 3.64 \\
\hline
\end{tabular}

reflected by their close scattering to the trend line, thus explaining the high $\mathrm{R}^{2}$ of 0.9303 and 0.9500 , respectively. The EY and TPC showed an adjusted $\mathrm{R}^{2}$ of 0.9000 and 0.8606 , respectively, which were the indication of accuracy and general availability of the polynomial model. Chua et al. [35] reported earlier that a well-fitted model should achieve a $\mathrm{R}^{2}$ value of at least 0.80 . Pertinently, the values of adequate precision which measures the signal to noise ratio were found high for EY (12.963) and TPC (14.360) ( $\geq 4$ ), further supported the reliability of the models to predict the best UAE conditions for the responses, EY and TPC.

The perturbation graph (Fig. 2(b)) depicted that EY was influenced by the ratio of solvent-to-solid (C) where the yield increased steadily as this factor was increased. This observation highlighted that use of higher volumes of solvent could facilitate a higher EY. Increasing ethanol concentration $\left(\mathrm{X}_{1}\right)$ appears to adversely affect EY. Conversely, the concentration of ethanol appears to appreciably influence TPC in the OPL 
Table 3. ANOVA of the quadratic model and lack of fit for EY

\begin{tabular}{|c|c|c|c|c|c|}
\hline Source & Sum of Squares & $\mathrm{df}$ & Mean Square & F Value & $\mathrm{p}$-value Prob $>\mathrm{F}$ \\
\hline Model & 360.09 & 14 & 25.72 & 13.35 & $<0.0001^{\star}$ \\
\hline $\mathrm{X}_{1}$ & 1.55 & 1 & 1.55 & 0.80 & 0.3852 \\
\hline $\mathrm{X}_{2}$ & 0.097 & 1 & 0.097 & 0.05 & 0.8255 \\
\hline $\mathrm{X}_{3}$ & 72.03 & 1 & 72.03 & 37.38 & $<0.0001^{\star}$ \\
\hline $\mathrm{X}_{4}$ & 7.04 & 1 & 7.04 & 3.65 & 0.0767 \\
\hline $\mathrm{X}_{1} \mathrm{X}_{2}$ & 5.45 & 1 & 5.45 & 2.83 & 0.1147 \\
\hline $\mathrm{X}_{1} \mathrm{X}_{3}$ & 0.36 & 1 & 0.36 & 0.19 & 0.6721 \\
\hline $\mathrm{X}_{1} \mathrm{X}_{4}$ & 3.28 & 1 & 3.28 & 1.70 & 0.2133 \\
\hline $\mathrm{X}_{2} \mathrm{X}_{3}$ & 12.82 & 1 & 12.82 & 6.65 & $0.0218^{\star}$ \\
\hline $\mathrm{X}_{2} \mathrm{X}_{4}$ & $4.23 \mathrm{E}-03$ & 1 & $4.23 \mathrm{E}-03$ & $2.19 \mathrm{E}-03$ & 0.9633 \\
\hline $\mathrm{X}_{3} \mathrm{X}_{4}$ & 1.37 & 1 & 1.37 & 0.71 & 0.4135 \\
\hline $\mathrm{X}_{1}^{2}$ & 30.19 & 1 & 30.19 & 15.67 & $0.0014^{\star}$ \\
\hline $\mathrm{X}_{2}^{2}$ & 80.55 & 1 & 80.55 & 41.81 & $<0.0001^{\star}$ \\
\hline $\mathrm{X}_{3}^{2}$ & 58.44 & 1 & 58.44 & 30.33 & $<0.0001^{\star}$ \\
\hline $\mathrm{X}_{4}^{2}$ & 89.65 & 1 & 89.65 & 46.53 & $<0.0001^{\star}$ \\
\hline Residual & 26.97 & 14 & 1.93 & & \\
\hline Lack of Fit & 24.33 & 10 & 2.43 & 3.69 & 0.1101 \\
\hline $\mathrm{R}^{2}$ & 0.9303 & & & & \\
\hline $\operatorname{Adj} R^{2}$ & 0.8606 & & & & \\
\hline Pure Error & 2.64 & 4 & 0.66 & & \\
\hline Corr Total & 387.06 & 28 & & & \\
\hline C.V.\% & 19.86 & & & & \\
\hline
\end{tabular}

extracts (OPLE) represented by the highly concave line $\left(\mathrm{X}_{1}\right)$ (Fig. 2(d)). This is consistent with a previous report describing the use of 50:50 hydro-ethanolic mixture as a better extracting solvent over pure water and ethanol [36].

ANOVA data for EY (Table 3) and TPC (Table 5) indicated that both models were highly significant ( $\mathrm{p}$ value $<0.0001)$. The high F-values for models, EY (13.35) and TPC (19) as compared to the tabulated $\mathrm{F}_{0.05(14,14)}$ of 2.48 , implied that the degree of freedom at $95 \%$ confidence level relative to the residual was significant. The adequacy of the EY and TPC models was further proven by the high $\mathrm{p}$-value for the lack of fit that corresponded to 0.1101 and 0.1929 , respectively, as well as the corresponding low F-values at 3.69 and 2.52. These values were lower than the tabulated $\mathrm{F}_{0.05(10,4)}(5.964)$, thus affirming that the lack of fit of each model was insignificant with regards to the pure error. The above data thus, conveyed that the model can adequately be used for optimizing the yield from OPL.

\section{Effects of UAE Experimental Factors on EY and TPC}

The percentage of EY from the UAE experiments varied from $2.49-14.38 \%$, with the maximum EY attained when using $35 \mathrm{~mL}$ of $50 \%$ ethanol at $60 \%$ of amplitude of UAE for an extraction time of $55 \mathrm{~min}$. The regression equation for EY and TPC are as follows (Eq. 5 and Eq. 6)

$\mathrm{EY}=3.64-0.36 \mathrm{X}_{1}-0.09 \mathrm{X}_{2}+2.45 \mathrm{X}_{3}-0.77 \mathrm{X}_{4}+1.17 \mathrm{X}_{1} \mathrm{X}_{2}$ $+0.3 \mathrm{X}_{1} \mathrm{X}_{3}+0.91 \mathrm{X}_{1} \mathrm{X}_{4}+1.79 \mathrm{X}_{2} \mathrm{X}_{3}-0.032 \mathrm{X}_{2} \mathrm{X}_{4}+0.59 \mathrm{X}_{3} \mathrm{X}_{4}$ $-2.16 \mathrm{X}_{1}^{2}+3.52 \mathrm{X}_{2}^{2}+3 \mathrm{X}_{3}^{2}+3.72 \mathrm{X}_{4}^{2}$

$\mathrm{TPC}=191.66+36.03 \mathrm{X}_{1}+1.43 \mathrm{X}_{2}-1.98 \mathrm{X}_{3}+6.01 \mathrm{X}_{4}-17.64 \mathrm{X}_{1} \mathrm{X}_{2}$

$-11.13 \mathrm{X}_{1} \mathrm{X}_{3}+3.01 \mathrm{X}_{1} \mathrm{X}_{4}-13.99 \mathrm{X}_{2} \mathrm{X}_{3}-3.96 \mathrm{X}_{2} \mathrm{X}_{4}-11.71 \mathrm{X}_{3} \mathrm{X}_{4}$ $-79.79 \mathrm{X}_{1}^{2}-14.36 \mathrm{X}_{2}^{2}+8.69 \mathrm{X}_{3}^{2}-17.07 \mathrm{X}_{4}^{2}$ 
Table 4. BBD experimental design and results for TPC

\begin{tabular}{|c|c|c|c|c|c|c|}
\hline Run & $\mathrm{X}_{1}$ & $\mathrm{X}_{2}$ & $\mathrm{X}_{3}$ & $\mathrm{X}_{4}$ & $\begin{array}{l}\text { Experimental TPC } \\
\text { (mg GAE/g) }\end{array}$ & $\begin{array}{c}\text { Expected TPC } \\
(\mathrm{mg} \mathrm{GAE} / \mathrm{g})\end{array}$ \\
\hline 1 & 50 & 5 & 15 & 60 & 186.30 & 172.53 \\
\hline 2 & 50 & 5 & 25 & 20 & 116.22 & 148.83 \\
\hline 3 & 50 & 30 & 35 & 20 & 196.98 & 187.00 \\
\hline 4 & 100 & 30 & 25 & 100 & 139.14 & 139.86 \\
\hline 5 & 50 & 30 & 25 & 60 & 193.34 & 191.66 \\
\hline 6 & 50 & 55 & 35 & 60 & 169.70 & 171.45 \\
\hline 7 & 0 & 30 & 25 & 20 & 68.52 & 55.78 \\
\hline 8 & 0 & 5 & 25 & 60 & 53.61 & 42.41 \\
\hline 9 & 50 & 30 & 25 & 60 & 183.19 & 191.66 \\
\hline 10 & 50 & 30 & 35 & 100 & 179.93 & 175.61 \\
\hline 11 & 0 & 55 & 25 & 60 & 77.49 & 80.55 \\
\hline 12 & 50 & 30 & 15 & 20 & 172.66 & 167.54 \\
\hline 13 & 50 & 5 & 35 & 60 & 205.61 & 196.57 \\
\hline 14 & 50 & 30 & 25 & 60 & 209.70 & 191.66 \\
\hline 15 & 100 & 5 & 25 & 60 & 162.24 & 149.74 \\
\hline 16 & 50 & 5 & 25 & 100 & 154.86 & 168.76 \\
\hline 17 & 50 & 55 & 25 & 20 & 152.05 & 159.61 \\
\hline 18 & 50 & 30 & 25 & 60 & 185.08 & 191.66 \\
\hline 19 & 0 & 30 & 35 & 60 & 83.33 & 93.69 \\
\hline 20 & 100 & 30 & 35 & 60 & 132.24 & 143.48 \\
\hline 21 & 100 & 30 & 15 & 60 & 158.59 & 169.70 \\
\hline 22 & 0 & 30 & 25 & 100 & 61.47 & 61.78 \\
\hline 23 & 100 & 30 & 25 & 20 & 134.14 & 121.81 \\
\hline 24 & 50 & 55 & 15 & 60 & 206.37 & 203.39 \\
\hline 25 & 0 & 30 & 15 & 60 & 65.16 & 75.38 \\
\hline 26 & 50 & 55 & 25 & 100 & 174.86 & 163.71 \\
\hline 27 & 100 & 55 & 25 & 60 & 115.57 & 117.33 \\
\hline 28 & 50 & 30 & 15 & 100 & 202.43 & 202.97 \\
\hline 29 & 50 & 30 & 25 & 60 & 186.98 & 191.66 \\
\hline
\end{tabular}

Based on the ANOVA, only the linear coefficient $\left(\mathrm{X}_{3}\right)$, cross product coefficient $\left(\mathrm{X}_{2} \mathrm{X}_{3}\right)$ and the quadratic term coefficients $\left(\mathrm{X}_{1}^{2}, \mathrm{X}_{2}^{2}, \mathrm{X}_{3}^{2}, \mathrm{X}_{4}^{2}\right)$ were significant in influencing EY by the UAE, as represented by their low pvalues $(\mathrm{p}<0.05)$ (Table 3$)$. These results implied that the deduced model was applicable to EY.

Conversely, the ANOVA for the TPC indicated only linear coefficient, $\left(\mathrm{X}_{1}\right)$, interactive coefficients, $\left(\mathrm{X}_{1} \mathrm{X}_{2}\right)$ and quadratic coefficients $\left(\mathrm{X}_{1}^{2}, \mathrm{X}_{2}^{2}, \mathrm{X}_{4}^{2}\right)$ were significant, corresponding to their low p-values $(\mathrm{p}<0.05)$ (Table 5). The outcome implied the deduced model was satisfactorily usable for estimating the optimized conditions for TPC. The experimental data for TPC achieved values between 53.61-209.70 mg GAE/g, for which a maximum TPC was obtained under conditions; solvent concentration of $50 \%$, extraction time of $30 \mathrm{~min}$, a $25 \mathrm{~mL} / \mathrm{g}$ solvent-to-solid ratio and sonication amplitude of $60 \%$. 
Table 5. ANOVA of the quadratic model and lack of fit for TPC

\begin{tabular}{|c|c|c|c|c|c|}
\hline Source & $\begin{array}{l}\text { Sum of } \\
\text { Squares }\end{array}$ & $\mathrm{df}$ & $\begin{array}{l}\text { Mean } \\
\text { Square }\end{array}$ & $\begin{array}{r}F \\
\text { Value }\end{array}$ & $\begin{array}{l}\text { p-value } \\
\text { Prob }>\text { F }\end{array}$ \\
\hline Model & 64613.48 & 14 & 4615.25 & 19.00 & $<0.0001^{\star}$ \\
\hline $\mathrm{X}_{1}$ & 15576.49 & 1 & 15576.49 & 64.11 & $<0.0001^{\star}$ \\
\hline $\mathrm{X}_{2}$ & 24.65 & 1 & 24.65 & 0.10 & 0.7548 \\
\hline $\mathrm{X}_{3}$ & 46.89 & 1 & 46.89 & 0.19 & 0.6672 \\
\hline $\mathrm{X}_{4}$ & 433.44 & 1 & 433.44 & 1.78 & 0.2030 \\
\hline $\mathrm{X}_{1} \mathrm{X}_{2}$ & 1244.33 & 1 & 1244.33 & 5.12 & $0.0401^{\star}$ \\
\hline $\mathrm{X}_{1} \mathrm{X}_{3}$ & 495.51 & 1 & 495.51 & 2.04 & 0.1752 \\
\hline $\mathrm{X}_{1} \mathrm{X}_{4}$ & 36.30 & 1 & 36.30 & 0.15 & 0.7049 \\
\hline $\mathrm{X}_{2} \mathrm{X}_{3}$ & 783.44 & 1 & 783.44 & 3.22 & 0.0942 \\
\hline $\mathrm{X}_{2} \mathrm{X}_{4}$ & 62.65 & 1 & 62.65 & 0.26 & 0.6195 \\
\hline $\mathrm{X}_{3} \mathrm{X}_{4}$ & 548.03 & 1 & 548.03 & 2.26 & 0.1554 \\
\hline $\mathrm{X}_{1}^{2}$ & 41291.80 & 1 & 41291.80 & 169.95 & $<0.0001^{\star}$ \\
\hline $\mathrm{X}_{2}^{2}$ & 1338.24 & 1 & 1338.24 & 5.51 & $0.0342^{x}$ \\
\hline $\mathrm{X}_{3}^{2}$ & 489.71 & 1 & 489.71 & 2.02 & 0.1776 \\
\hline $\mathrm{X}_{4}^{2}$ & 1889.20 & 1 & 1889.20 & 7.78 & $0.0145^{\rtimes}$ \\
\hline Residual & 3401.60 & 14 & 242.97 & & \\
\hline Lack of Fit & 2936.40 & 10 & 293.64 & 2.52 & 0.1929 \\
\hline $\mathrm{R}^{2}$ & 0.95 & & & & \\
\hline Adj $R^{2}$ & 0.90 & & & & \\
\hline Pure Error & 465.20 & 4 & 116.30 & & \\
\hline Corr Total & 68015.08 & 28 & & & \\
\hline C.V.\% & 10.45 & & & & \\
\hline
\end{tabular}

The Mutual Interaction of Process Variables on the EY and TPC of E. guineensis Leaves

\section{The mutual interaction of process variables of EY}

Since the ANOVA indicated that the interaction between factors, extraction time vs solvent-to-solid ratio $\left(\mathrm{X}_{2} \mathrm{X}_{3}\right)$ was the only significant interactive term $(\mathrm{p}$-value $=$ 0.0218) (Table 3), only the corresponding contour and 3$\mathrm{D}$ response surface plots for the term were discussed in the following section. Interaction between the two factors can be better understood by holding the solvent concentration and sonication amplitude at their central values, corresponding to $50 \%$ and $60 \%$. Fig. 3 illustrated that EY as high as $12.45 \%$ was obtainable when both factors, extraction time and solvent-to-solid ratio were set close to their upper limits, at $55 \mathrm{mins}$ and $35 \mathrm{~mL} / \mathrm{g}$, respectively. It was evident that the factor of solvent-to- solid ratio, $\mathrm{X}_{3}(\mathrm{~F}$-value $=37.38)$ has a greater influence over extraction time, $\mathrm{X}_{2}(\mathrm{~F}$-value $=0.05)$ to maximize the EY of OPLE. Additionally, their synergistic interaction $\left(+1.79 \mathrm{X}_{2} \mathrm{X}_{3}\right)($ Eq. 5) implied that elevating both factors to their maximum values can favor better yields of the OPLE. This might be due to the use of a larger solventto-solid ratio that tends to promote a greater mass transfer of trapped plant solutes in cells into the surrounding medium, as previously described by similar studies [34,37]. This, in turn, led to an improved EY from the powdered OPL.

As observed previously, increasing the solvent-tosolid ratio has been agreed to be one of the key factors to promote higher yields from plant materials [38]. Sheng [39] described that cavitational effect from microjets generated from collisions of acoustic bubbles was the 

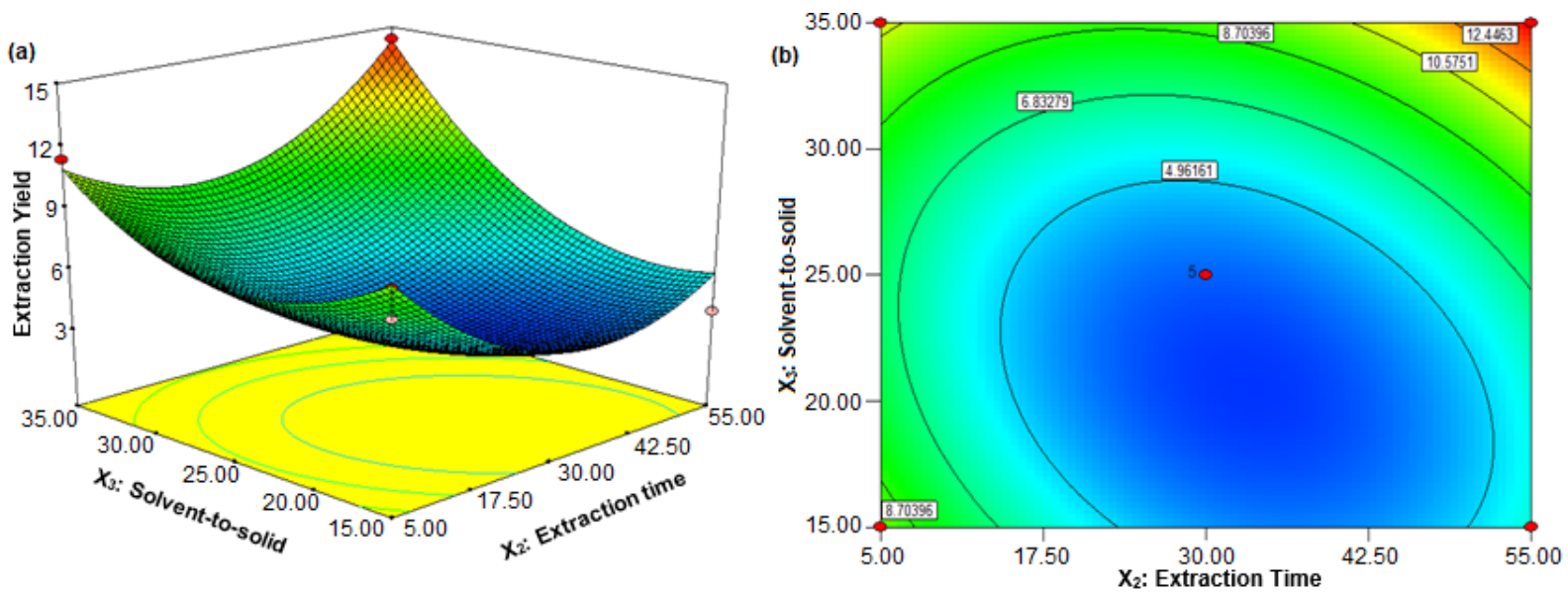

Fig 3. (a) Response surface (3D) and (b) contour plot (2D) showing the effects of extraction time and solvent-to-solid ratio on $\mathrm{EY}$

trigger mechanism that caused the extensive swelling and disruption of plant cell structures that followed the ultrasonic treatment. This perpetually caused more solvent molecules from the surrounding extractive medium to diffuse in and out of the cells, thus liberating more bioactive compounds. Mass transfer of the solutes into the solvent is facilitated, thereby increasing EY.

\section{The mutual interaction of process variables of TPC}

Data on the interactive effect of varying extraction time and solvent concentration $\left(\mathrm{X}_{1} \mathrm{X}_{2}\right)$ on TPC, investigated at a constant solvent-to-solid ratio of $25 \mathrm{~mL} / \mathrm{g}$ and sonication of the amplitude of $60 \%$ is shown in Fig. 4. As seen here, the effect of solvent concentration on the TPC was more impacting than extraction time (Table 5), corresponding to an F-value of 64.11 as compared to 0.1 for extraction time. Their mutual interaction appears significant because of a small p-value (0.0401), but the factors were antagonistically related $\left(-17.64 \mathrm{X}_{1} \mathrm{X}_{2}\right)$ to affect TPC (Eq. 6). A TPC of as much as $191.65 \mathrm{mg} \mathrm{GAE} / \mathrm{g}$ was possible using an ethanol concentration and extraction time of $50 \%$ and $30 \mathrm{~min}$, respectively. It was clear that further increasing the factors beyond their optimal limits led to the general decline in the TPC of the OPLE.

López [36] reported obtaining the highest TPC when they used a mixture of 50\% ethanol and water. This has to do with the polarity of plant phenolic compounds being higher than water but lower than absolute ethanol, thus a 50\% ethanol:water mixed would provide adequate polarity to solubilize more of the
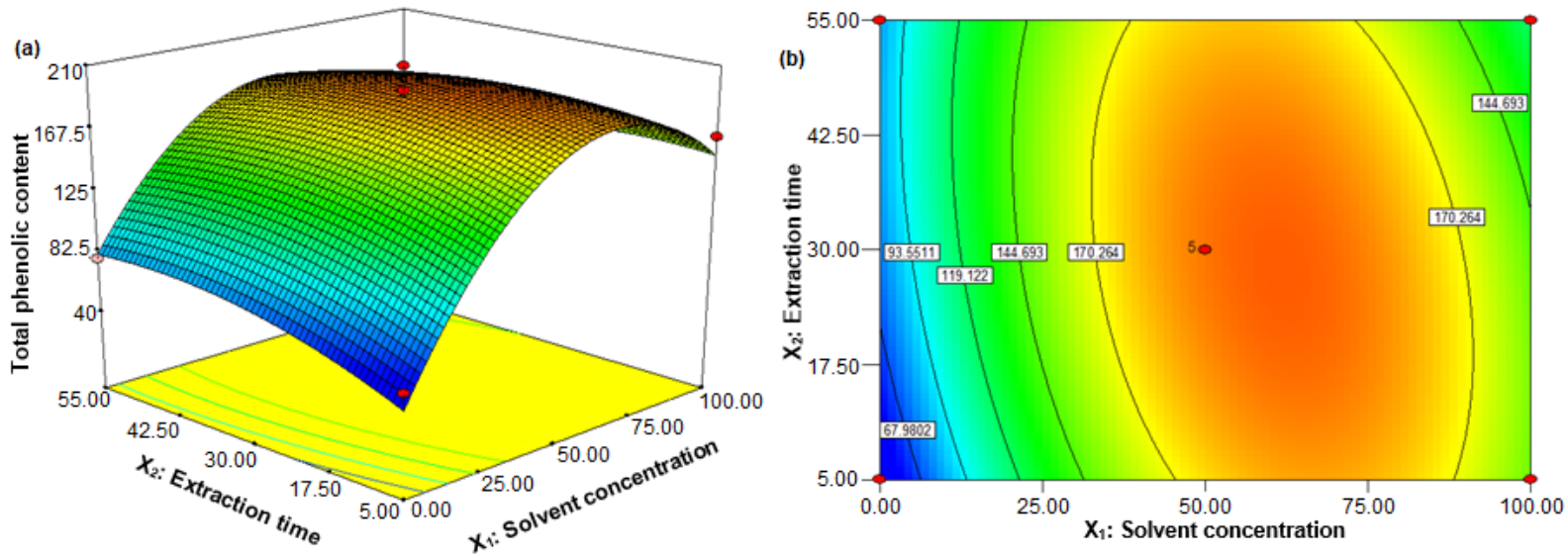

Fig 4. (a) Response surface (3D) and (b) contour plots (2D) showing the effects of solvent concentration and extraction time on TPC 
extracted OPL compounds. Correspondingly, the same solvent mixture of ethanol:water can act a good swelling agent to cause the bursting of cell walls of OPL, permitting higher entry of the solvent mixture into the cells [37]. Contrariwise, a too high concentration of water would not improve the TPC of the UAE technique. This is because the naturally high viscosity of water can substantially lower the mass transfer of phenolic compounds out from the cell walls of the OPL into the extractive medium. The high dielectric constant of water can increase the polarity indices of ethanol with water [40] which would not help to improve the TPC of UAE process [41].

Whilst, an extraction time of $30 \mathrm{~min}$ was seen as sufficient to enhance extraction of phenolic compounds from powdered OPL, a longer extraction time can allow a higher cavitation effect to physically disrupt plant cells [37] of OPL, thereby releasing higher contents of phenolic compounds into the extractive medium. The study found the value of TFC was the highest at $181.46 \mathrm{mg} \mathrm{CAE} / \mathrm{g}$. This agreed with a previous study that showed quantities of extracted flavonoids tended to be maximum with increasing ethanol concentration in the solvent mixture of ethanol/water. Thus, directly influencing the quantity and composition of the flavonoids and polyphenolic compounds extracted from a plant material [42].

\section{Comparison of Conventional Extraction Techniques with UAE}

\section{Comparison of UAE with Soxhlet extraction and maceration}

As shown in Table 6, it was evident that the EY and TPC obtained from ultrasonically treated OPL samples were considerably higher than that obtained by Soxhlet extraction and maceration techniques. EY and TPC from Soxhlet extraction samples were $6.86 \%$ and $102.13 \mathrm{mg}$ GAE/g, respectively, whilst maceration yielded the least EY and TPC corresponding to $3.73 \%$ and $85.23 \mathrm{mg} \mathrm{GAE} / \mathrm{g}$.

Table 6. Comparison of UAE of highest EY and TPC obtained by BBD with soxhlet extraction and maceration

\begin{tabular}{lcc}
\hline Methods & EY $(\%)$ & TPC (mg CAE/g) \\
\hline UAE & 14.38 & 209.7 \\
Soxhlet extraction & 6.86 & 102.13 \\
Maceration & 3.73 & 85.23 \\
\hline
\end{tabular}

The results conclusively showed that the UAE technique was efficient in releasing higher quantities of the plant solutes into the solvent layer, similar to observations by earlier studies [43-44]. The lower TPC values seen in the Soxhlet extracted sample was possibly due to a higher decomposition of phenolic compounds during reflux. Whereas, vigorous shaking alone, in the maceration process was ineffective in bringing out much of the bioactive compounds into the extractive liquid, hence explaining the lowest EY and TPC values [45].

In essence, the UAE technique is seemingly more attractive due to a short optimal extraction time of 55 and $30 \mathrm{~min}$, as well as requiring lower quantities of solvents to give the highest EY (14.38\%) and TPC (209.70 mg GAE/g). This is a marked difference from the Soxhlet extraction and maceration techniques that required $24 \mathrm{~h}$ to achieve their highest $\mathrm{EY}(6.86 \%$ and $3.73 \%$ ) and TPC (102.13 and $85.23 \mathrm{mg} \mathrm{GAE} / \mathrm{g}$ ), thus proving that UAE is a more efficient in yielding better EY and TPC from powdered OPL.

\section{Scanning electron microscopy (SEM) of untreated, Soxhlet extracted, macerated and UAE samples}

SEM was employed to observe the physical consequence of sonication in altering cellular structures of OPL. Micrographs in Fig. 5(a-c) show cell walls of
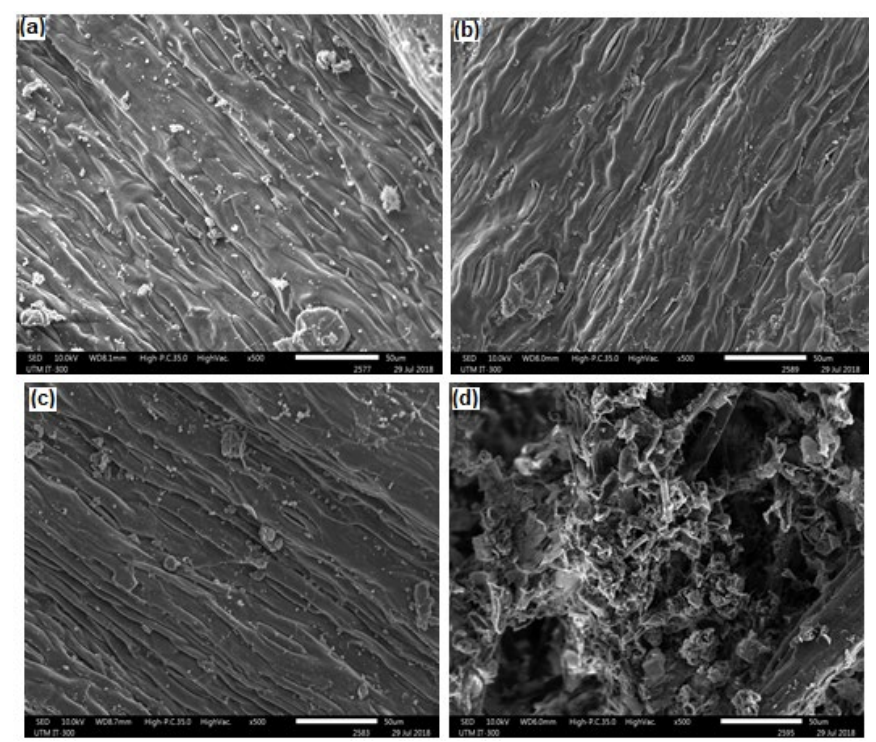

Fig 5. SEM micrographs of different OPL samples before and after extraction at 500x magnification. (a) nonextracted sample, (b) Soxhlet, (c) maceration and (d) UAE 


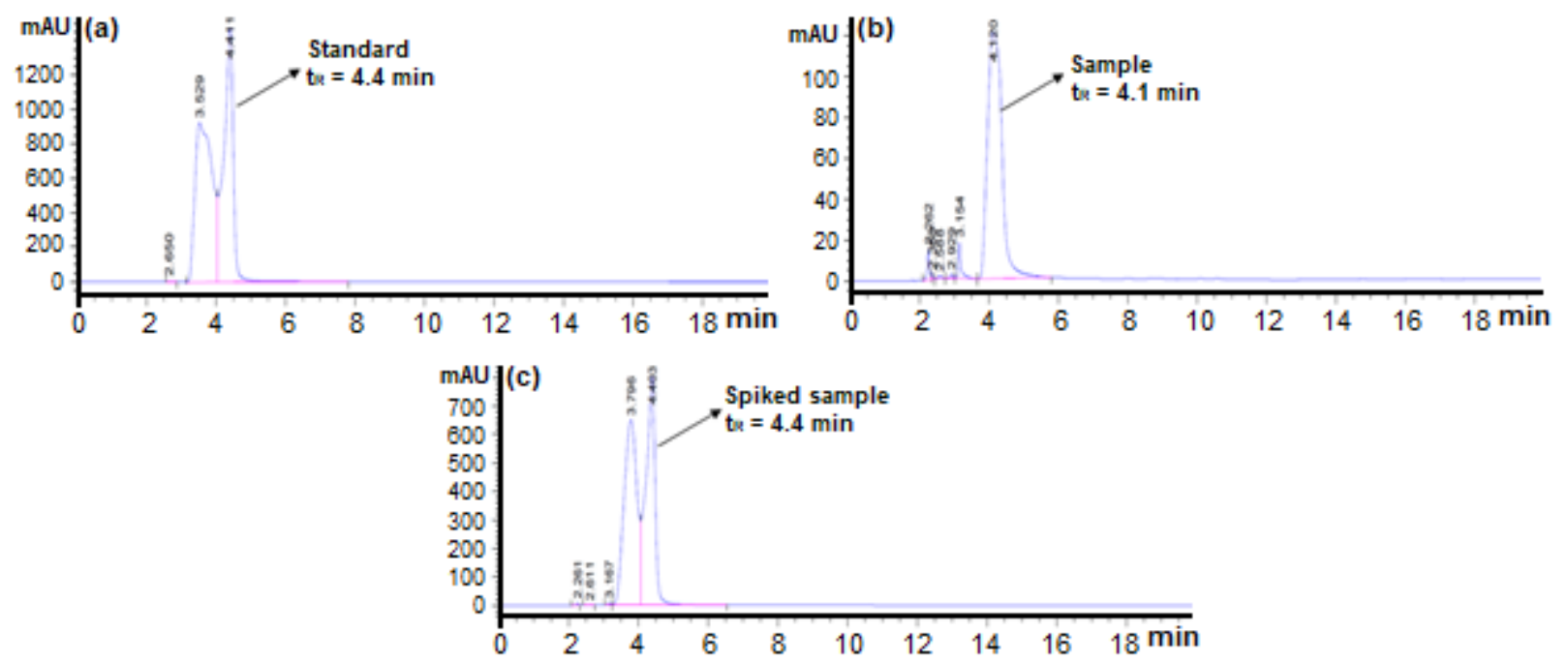

Fig 6. HPLC analysis of (a) gallic acid standard, (b) the highest TPC crude and (c) the highest TPC crude spiked with gallic acid standard
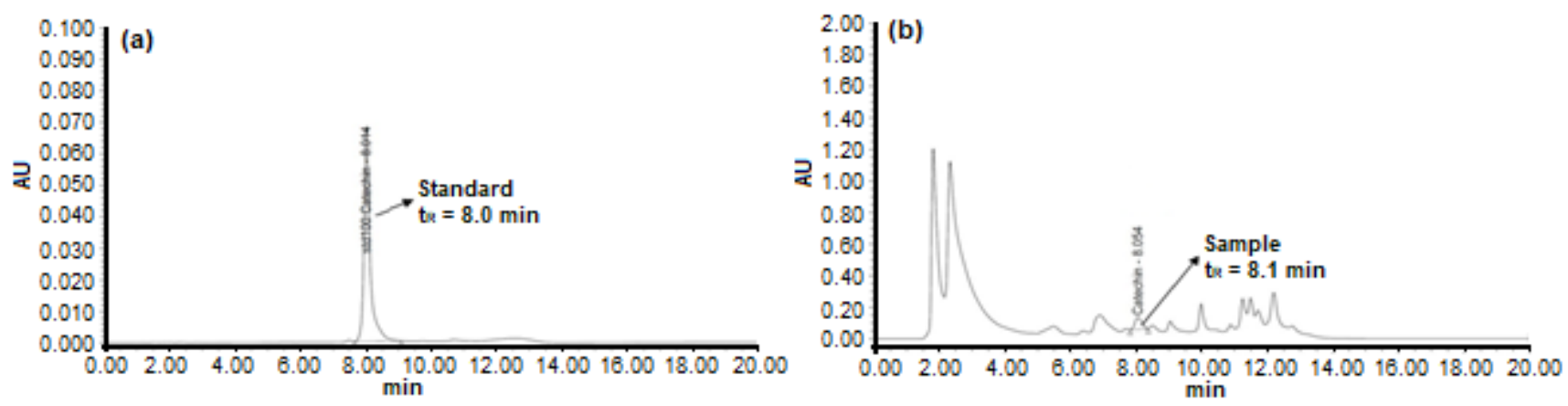

Fig 7. HPLC analysis of (a) catechin standard and (b) the highest TPC crude

untreated E. guineensis, Soxhlet extraction, and maceration. The cellular structures of Soxhlet and maceration treated samples did appear quite wrinkled but, in general, remained quite intact. This however, was very different for the UAE treated sample (Fig. 5(d)) that showed a widespread structure of burst cell fragments on the surface of OPL. The micrographs conclusively supported the theoretical acoustically-induced rupturing and disintegrating plant cell walls by ultrasonication [46], explicitly proving UAE as an efficient method to achieve the highest EY and TPC from OPL, as compared to techniques by maceration and Soxhlet extraction.

\section{High-Performance Liquid Chromatography of OPLE}

High-performance liquid chromatography (HPLC) analysis was performed on the highest TPC crude to reveal the presence of two major antioxidants extracted from the leaves of E. guineensis. The compounds were found to be gallic acid (Fig. 6) and catechin (Fig. 7), with the retention times, $t_{R}$ for the gallic acid standard, crude TPC and the highest TPC crude spiked with gallic acid standard as $4.4,4.1$, and $4.4 \mathrm{~min}$, respectively. The standard for catechin and the highest TPC crude were eluted at retention times, $t_{R} 8.0 \mathrm{~min}$ and $8.1 \mathrm{~min}$, respectively, which was in good agreement with a study by Ahmad [47] showing catechin as the main flavonoid (natural antioxidant) in OPLE.

\section{- CONCLUSION}

In the present paper, RSM optimization was successfully employed for attaining the highest EY and TPC in OPLE. Influences of ethanol concentration, extraction time, solvent-to-solid ratio and sonication amplitude of UAE were evaluated using a four-factor- 
three-level BBD, in which optimal UAE conditions yielded the highest EY at 14.38\% [50\% (v/v) ethanol-water ratio, $55 \mathrm{~min}, 35 \mathrm{~mL} / \mathrm{g}$ solvent-to-solid ratio, $60 \%$ sonication amplitude] and TPC of $209.70 \mathrm{mg} \mathrm{GAE} / \mathrm{g}$ [50\% (v/v) ethanol-water ratio, $30 \mathrm{~min}, 25 \mathrm{~mL} / \mathrm{g}$ solvent-tosolid ratio and $60 \%$ sonication amplitude], respectively, where compounds, gallic acid and catechin were the two main phytochemicals extracted from the OPL. The ANOVA suggested that the factor solvent concentration (F-value $=64.11)$ was the most influential in governing efficacy of the UAE of powdered OPL. Most importantly, the study envisages the UAE as a promisingly exceptional technique to extract high quantities of valuable plantbased bioactive compounds.

\section{- ACKNOWLEDGMENTS}

This work was supported by the Fundamental Research Grant Scheme (QJ130000.2526.17H48) from the Ministry of Higher Education. The author is grateful to Universiti Teknologi Malaysia for funding her Zamalah Scholarship.

\section{- REFERENCES}

[1] Dal Prá, V., Soares, J.F., Monego, D.L., Vendruscolo, R.G., Freire, D.M.G., Alexandri, M., and da Rosa, M.B. 2016, Extraction of bioactive compounds from palm (Elaeis guineensis) pressed fiber using different compressed fluids, J. Supercrit. Fluids, 112, 51-56.

[2] Dal Prá, V., Lunelli, F.C., Vendruscolo, R.G., Martins, R., Wagner, R., Lazzaretti Jr, A.P., Freire, D.M.G., Alexandri, M., Koutinas, M., Mazutti, M.A., and da Rosa, M.B., 2017, Ultrasound-assisted extraction of bioactive compounds from palm pressed fiber with high antioxidant and photoprotective activities, Ultrason. Sonochem., 36, 362-366.

[3] Obahiagbon, F., 2012, A review: Aspects of the African oil palm (Elaeis guineesis Jacq.) and the implications of its bioactives in human health, Am. J. Biochem. Mol. Biol., 2 (3), 106-119.

[4] Sumathi, S., Chai, S., and Mohamed, A., 2008, Utilization of oil palm as a source of renewable energy in Malaysia, Renewable Sustainable Energy Rev., 12 (9), 2404-2421.
[5] Onoja, E., Chandren, S., Razak, F.I.A., and Wahab, R.A., 2018, Enzymatic synthesis of butyl butyrate by Candida rugosa lipase supported on magnetizednanosilica from oil palm leaves: Process optimization, kinetic and thermodynamic study, J. Taiwan Inst. Chem. Eng., 91, 105-118.

[6] Onoja, E., Chandren, S., Razak, F.I.A., Mahat, N.A., and Wahab, R.A., 2018, Oil palm (Elaeis guineensis) biomass in Malaysia: The present and future prospects, Waste Biomass Valorization, 1-19.

[7] Tahir, N.I., Shaari, K., Abas, F., Parveez, G.K.A., Ishak, Z., and Ramli, U.S., 2012, Characterization of apigenin and luteolin derivatives from oil palm (Elaeis guineensis Jacq.) leaf using LC-ESI-MS/MS, J. Agric. Food Chem., 60 (45), 11201-11210.

[8] Mohamed, S., 2014, Oil palm leaf: A new functional food ingredient for health and disease prevention, Int. J. Food Process. Technol., 5 (2), 1000300.

[9] Elias, N., Chandren, S., Attan, N., Mahat, N.A., Razak, F.I.A., Jamalis, J., and Wahab, R.A., 2017, Structure and properties of oil palm-based nanocellulose reinforced chitosan nanocomposite for efficient synthesis of butyl butyrate, Carbohydr. Polym., 176, 281-292.

[10] Sundram, K., Sambanthamurthi, R., and Tan, Y.A., 2003, Palm fruit chemistry and nutrition, Asia Pac. J. Clin. Nutr., 12 (3), 355-362.

[11] Mba, O.I., Dumont, M.J., and Ngadi, M., 2015, Palm oil: Processing, characterization and utilization in the food industry-A review, Food Biosci., 10, 26-41.

[12] Ofori-Boateng, C., Lee, K.T., and Saad, B., 2014, A biorefinery concept for simultaneous recovery of cellulosic ethanol and phenolic compounds from oil palm fronds: Process optimization, Energy Convers. Manage., 81, 192-200.

[13] Yusof, N.Z., Abd Gani, S.S., Hasan, Z.A.A., and Idris, Z., 2018, Skin and eye irritation assessment of oil palm (Elaeis guineensis) leaf extract for tropical application, Int. J. Toxicol., 37 (4), 335-343.

[14] Jaffri, J.M., Mohamed, S., Ahmad, I.N., Mustapha, N.M., Manap, Y.A., and Rohimi, N., 2011, Effects of catechin-rich oil palm leaf extract on normal and 
hypertensive rats' kidney and liver, Food Chem., 128 (2), 433-441.

[15] Yusof, N.Z., Abd Gani, S.S., Siddiqui, Y., Mohd Mokhtar, N.F., and Hasan, Z.A.A. 2016, Potential uses of oil palm (Elaeis guineensis) leaf extract in topical application, J. Oil Palm Res., 28 (4), 520-530.

[16] Sharmila, G., Nikitha, V., Ilaiyarasi, S., Dhivya, K., Rajasekar, V., Kumar, N.M., Muthukumaran, K., and Muthukumaran, C., 2016, Ultrasound assisted extraction of total phenolics from Cassia auriculata leaves and evaluation of its antioxidant activities, Ind. Crops Prod., 84, 13-21.

[17] Hammi, K.M., Jdey, A., Abdelly, C., Majdoub, H., and Ksouri, R., 2015, Optimization of ultrasoundassisted extraction of antioxidant compounds from Tunisian Zizyphus lotus fruits using response surface methodology, Food Chem., 184, 80-89.

[18] Neo, Y.P., Ariffin, A., Tan, C.P., and Tan, Y.A., 2010, Phenolic acid analysis and antioxidant activity assessment of oil palm (E. guineensis) fruit extracts, Food Chem., 122 (1), 353-359.

[19] Rao, P., and Rathod, V., 2017, "Phytochemicals: An Insight to Modern Extraction Technologies and Their Applications" in Ingredients Extraction by Physicochemical Methods in Food, Elsevier, 495-521.

[20] Wang, X., Wu, Y., Chen, G., Yue, W., Liang, Q., and $\mathrm{Wu}$, Q., 2013, Optimisation of ultrasound assisted extraction of phenolic compounds from Sparganii rhizoma with response surface methodology, Ultrason. Sonochem., 20 (3), 846-854.

[21] Wu, Y., Wang, X., Xue, J., and Fan, E., 2017, Plant phenolics extraction from Flos chrysanthemi: Response surface methodology based optimization and the correlation between extracts and free radical scavenging activity, J. Food Sci., 82 (11), 2726-2733.

[22] Xie, Z., Sun, Y., Lam, S., Zhao, M., Liang, Z., Yu, X., Yang, D., and Xu, X., 2014, Extraction and isolation of flavonoid glycosides from Flos Sophorae Immaturus using ultrasonic-assisted extraction followed by high-speed countercurrent chromatography, J. Sep. Sci., 37 (8), 957-965.

[23] Amiri, S., Shakeri, A., Sohrabi, M.R., Khalajzadeh, S., and Ghasemi, E., 2019, Optimization of ultrasonic assisted extraction of fatty acids from Aesculus hippocastanum fruit by response surface methodology, Food Chem., 271, 762-766.

[24] Deng, G.F., Xu, D.P., Li, S., and Li, H.B., 2015, Optimization of ultrasound-assisted extraction of natural antioxidants from sugar apple (Annona squamosa L.) peel using response surface methodology, Molecules, 20 (11), 20448-20459.

[25] Zhu, C.P., Zhai, X.C., Li, L.Q., Wu, X.X., and Li, B., 2015, Response surface optimization of ultrasoundassisted polysaccharides extraction from pomegranate peel, Food Chem., 177, 139-146.

[26] Manan, F.M.A., Attan, N., Zakaria, Z., Keyon, A.S.A., and Wahab, R.A. 2018, Enzymatic esterification of eugenol and benzoic acid by a novel chitosan-chitin nanowhiskers supported Rhizomucor miehei lipase: Process optimization and kinetic assessments, Enzyme Microb. Technol., 108, 42-52.

[27] Mohamad, N., Huyop, F., Aboul-Enein, H.Y., Mahat, N.A., and Wahab, R.A., 2015, Response surface methodological approach for optimizing production of geranyl propionate catalysed by carbon nanotubes nanobioconjugates, Biotechnol. Biotechnol. Equip., 29 (4), 732-739.

[28] Ali, A., Lim, X.Y., Chong, C.H., Mah, S.H., and Chua, B.L, 2018, Optimization of ultrasoundassisted extraction of natural antioxidants from Piper betle using response surface methodology, LWT, 89, 681-688.

[29] Dróżdż, P., Šěžienè, V., and Pyrzynska, K., 2017, Phytochemical properties and antioxidant activities of extracts from wild blueberries and lingonberries, Plant Foods Hum. Nutr., 72 (4), 360-364.

[30] Josipović, A., Sudar, R., Sudarić, A., Jurković, V., Kočar, M.M., and Kulundžić, A.M., 2016, Total phenolic and total flavonoid content variability of soybean genotypes in eastern Croatia, Croat. J. Food. Sci. Technol., 8 (2), 60-65.

[31] Zhang, H., Birch, J., Xie, C., Yang, H., Dias, G., Kong, L., and Bekhit, A.E.D. 2018, Optimization of extraction parameters of antioxidant activity of extracts from New Zealand and Chinese Asparagus 
officinalis L root cultivars, Ind. Crops Prod., 119, 191200.

[32] Xu, D.P., Zheng, J., Zhou, Y., Li, Y., Li, S., and Li, H.B., 2017, Ultrasound-assisted extraction of natural antioxidants from the flower of Limonium sinuatum: Optimization and comparison with conventional methods, Food Chem., 217, 552-559.

[33] Yang, B., Liu, X., and Gao, Y., 2009, Extraction optimization of bioactive compounds (crocin, geniposide and total phenolic compounds) from Gardenia (Gardenia jasminoides Ellis) fruits with response surface methodology, Innovative Food Sci. Emerg. Technol., 10 (4), 610-615.

[34] Marzuki, N.H.C., Hamid, M.A., and Wahab, R.A., 2018, Assessment of fatty acid composition and response surface optimization of ultrasonic-assisted extraction of phenolic compounds from Pouteria campechiana pulp, Malays. J. Fundam. Appl. Sci., 14 (2), 269-277.

[35] Chua, S.C., Tan, C.P., Mirhosseini, H., Lai, O.M., Long, K., and Baharin, B.S., 2009, Optimization of ultrasound extraction condition of phospholipids from palm-pressed fiber, J. Food Eng., 92 (4), 403409.

[36] López, C.J., Caleja, C., Prieto, M., Barreiro, M.F., Barros, L., and Ferreira, I.C.F.R., 2018, Optimization and comparison of heat and ultrasound assisted extraction techniques to obtain anthocyanin compounds from Arbutus unedo L. fruits, Food Chem., 264, 81-91.

[37] Jibril, S., Basar, N., Sirat, H.M., Wahab, R.A., Mahat, N.A., Nahar, L., and Sarker, S.D., 2018, Application of Box-Behnken design for ultrasound-assisted extraction and recycling preparative HPLC for isolation of anthraquinones from Cassia singueana, Phytochem. Anal., 30 (1), 101-109.

[38] Shalmashi, A., 2009, Ultrasound-assisted extraction of oil from tea seeds, J. Food Lipids, 16 (4), 465-474.

[39] Sheng, Z., Wang, Y., Wan, P., and Li, Y., 2014, Ultrasound-assisted extraction of total flavonoids from leaves of Syringa oblata Lindl., Lat. Am. Appl. Res., 44 (2), 131-135.

[40] Şahin, S., and Şamlı, R., 2013, Optimization of olive leaf extract obtained by ultrasound-assisted extraction with response surface methodology, Ultrason. Sonochem., 20 (1), 595-602.

[41] Ghitescu, R.E., Volf, I., Carausu, C., Bühlmann, A.M., Gilca, I.A., and Popa, V.I., 2015, Optimization of ultrasound-assisted extraction of polyphenols from spruce wood bark, Ultrason. Sonochem., 22, 535-541.

[42] Tomšik, A., Pavlić, B., Vladić, J., Ramić, M., Brindza, J., and Vidović, S., 2016, Optimization of ultrasound-assisted extraction of bioactive compounds from wild garlic (Allium ursinum L.), Ultrason. Sonochem., 29, 502-511.

[43] Esclapez, M., García-Pérez, J., Mulet, A., and Cárcel, J., 2011, Ultrasound-assisted extraction of natural products, Food Eng. Rev., 3 (2), 108.

[44] Vajić, U.J., Grujić-Milanović, J., Živković, J., Šavikin, K., Gođevac, D., Miloradović, Z., Bugarski, B., and Mihailović-Stanojević, N., 2015, Optimization of extraction of stinging nettle leaf phenolic compounds using response surface methodology, Ind. Crops Prod., 74, 912-917.

[45] Li, T., Qu, X.Y., Zhang, Q.A., and Wang, Z.Z., 2012, Ultrasound-assisted extraction and profile characteristics of seed oil from Isatis indigotica Fort, Ind. Crops Prod., 35 (1), 98-104.

[46] Minjares-Fuentes, R., Femenia, A., Garau, M., Meza-Velázquez, J., Simal, S., and Rosselló, C., 2014, Ultrasound-assisted extraction of pectins from grape pomace using citric acid: A response surface methodology approach, Carbohydr. Polym., 106, 179-189.

[47] Ahmad, N., Hasan, Z.A.A., Muhamad, H., Bilal, S.H., Yusof, N.Z., and Idris, Z., 2018, Determination of total phenol, flavonoid, antioxidant activity of oil palm leaves extracts and their application in transparent soap, J. Oil Palm Res., 30 (2), 315-325. 